\title{
Cannabinoid Hyperemesis: An Erratic Syndrome Linked with Cannabis Abuse
}

\section{Md. Sahab Uddin ${ }^{1 *}$ and Md. Shah Amran ${ }^{2}$}

${ }^{1}$ Department of Pharmacy, Southeast University, Dhaka, Bangladesh

${ }^{2}$ Department of Pharmaceutical Chemistry, University of Dhaka, Dhaka, Bangladesh

\section{Editorial}

Cannabinoid hyperemesis syndrome (CHS) is characterized by chronic cannabis use, recurrent episodes of intractable nausea and vomiting, frequent hot bathing and abdominal pain [1]. The syndrome was first described by Allen et al. [2], and later Sontineni et al. [3] who proposed abridged clinical diagnostic criteria. Simonetto et al. by appraising all PubMed indexed journals with case reports and case series on CHS, reported a case series of 98 patients [4]. This study confirmed the previously stated outcomes. The researchers avowed that CHS should be measured in younger patients with chronic cannabis use and repeated nausea, vomiting, as well as pain in the abdominal. Amid illicit drug, cannabis is the utmost typically used this drug in the world [5].

In line with the 2015 National Survey on Drug Use and Health, 22.2 million people have used cannabinoids in the past month [6]. The prevalence of use is higher in men than women, a gender gap that extended in the years 2007 to 2014 (Figure 1) [7]. The number of people affected is not diaphanous as of 2015 [8]. Cannabis use is linked with copious acute and chronic adverse effects as stated earlier such as vomiting, followed by cyclic vomiting syndrome, intense feelings of nausea and accompanying symptoms, abdominal discomfort and compulsive hot bathing behaviour [3]. Habboushe and Sedor, reported that CHS can lead to snags, for example, acute renal failure (ARF) [9].

The pathogenesis of CHS is covert, several mechanistic theories attempting to explain the exact pathology. These notions fall into two themes: dose reliant accumulation of cannabinoids and associated

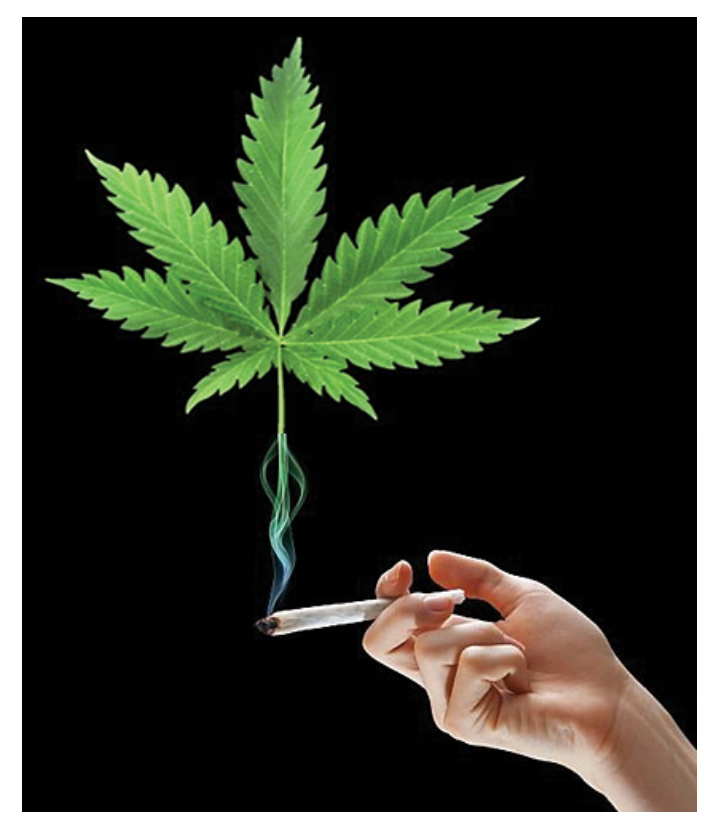

Figure 1: Cannabinoids are the illicit drug most likely to be used by teenagers and its abuse lead to cannabinoid hyperemesis syndrome. The treatment of this syndrome is supportive and emphases on ceasing cannabis use. effects of cannabinoid toxicity; and the functionality of cannabinoid receptors in the brain and predominantly in the hypothalamus that controls body temperature and the digestive system [10]. Chang and Windish offer an outline of substantiating proof for these theories; however, the mechanisms by which cannabis engender controls nausea and the adverse magnitudes of chronic cannabis toxicity remain cryptic [11].

Cannabinoid binds to two kinds of G-protein coupled cannabinoid receptors, $\mathrm{CB}_{1}$ and $\mathrm{CB}_{2}$ that act by inhibiting adenylate cyclase [12]. In conjunction with the discovery of the $\mathrm{CB}_{1}$ and $\mathrm{CB}_{2}$ receptors has been the identification of endogenous arachidonic acid derivatives that bind to these receptors called endogenous cannabinoids, or endocannabinoids [13]. The therapeutic potential of cannabinoids has been identified and these compounds are utilized as antiemetics for controlling nausea and vomiting as well as in the progressive phases of ailments such as cancer and acquired immune deficiency syndrome [14].

The acute incidents of CHS typically last for 24 to $48 \mathrm{~h}$ and the cessation of use is effective. Generally, 1 to 3 months is required for perfect recovery [15]. Numerous medications for nausea and vomiting are ineffective for this syndrome. Chen and McCarron stated that relief has been reported with lorazepam and haloperidol [16]. Furthermore, evaluating for dehydration owing to vomiting and hot showers is imperative as it can lead to ARF and resolved with intravenous hydration [16].

CHS is a novel and under-documented clinical entity. Advanced studies are obligatory to control this disease prevalence and its other epidemiological features, natural antiquity as well as pathophysiology. Further treatments are enforced and exertions to stop cannabis abuse are supreme.

\section{Acknowledgements}

The authors wish to thank the anonymous reviewer(s)/editor(s) of this article for their constructive reviews.

\section{Competing Interests}

The authors state no competing interests.

\section{References}

1. Sorensen CJ, DeSanto K, Borgelt L, Phillips KT, Monte AA (2017) Cannabinoid hyperemesis syndrome: Diagnosis, pathophysiology, and treatment-a

*Corresponding author: Md. Sahab Uddin, Department of Pharmacy, Southeast University, Dhaka, Bangladesh, Tel: +880 1710220110; E-mail: msu neuropharma@hotmail.com, msu-neuropharma@hotmail.com

Received: January 23, 2018; Accepted: January 23, 2018; Published: January 29, 2018

Citation: Uddin MS, Amran MS (2018) Cannabinoid Hyperemesis: An Erratic Syndrome Linked with Cannabis Abuse. J Psychiatry 21: e116. doi:10.4172/2378 5756.1000e116

Copyright: @ 2018 Uddin MS, et al. This is an open-access article distributed under the terms of the Creative Commons Attribution License, which permits unrestricted use, distribution, and reproduction in any medium, provided the original author and source are credited 
Citation: Uddin MS, Amran MS (2018) Cannabinoid Hyperemesis: An Erratic Syndrome Linked with Cannabis Abuse. J Psychiatry 21 : e116. doi:10.4172/2378-5756.1000e116

systematic review. J Med Toxicol 13: 71-87.

2. Allen JH, De Moore GM, Heddle R, Twartz JC (2004) Cannabinoid hyperemesis: Cyclical hyperemesis in association with chronic cannabis abuse. Gut 53: 1566-1570.

3. Sontineni SP, Chaudhary S, Sontineni V, Lanspa SJ (2009) Cannabinoid hyperemesis syndrome: Clinical diagnosis of an underrecognised manifestation of chronic cannabis abuse. World J Gastroenterol 15: 1264-1266

4. Simonetto DA, Oxentenko AS, Herman ML, Szostek JH (2012) Cannabinoid hyperemesis: A case series of 98 patients. Mayo Clin Proc 87: 114-119.

5. Leggett T, United Nations Office on Drugs and Crime (2006) A review of the world cannabis situation. Bull Narc 58: 1-155

6. National Institute on Drug Abuse (2017) What is the scope of marijuana use in the United States?

7. Carliner H, Mauro PM, Brown QL, Shmulewitz D, Rahim-Juwel R, et al. (2016) The widening gender gap in marijuana use prevalence in the U.S. during a period of economic change, 2002-2014. Drug Alcohol Depend 170: 51-58.

8. Lu ML, Agito MD (2015) Cannabinoid hyperemesis syndrome: Marijuana is both antiemetic and proemetic. Cleveland Clinic J Med 82: 429-34.
9. Habboushe J, Sedor J (2014) Cannabinoid hyperemesis acute renal failure: A common sequela of cannabinoid hyperemesis syndrome. Am J Emerg Med 32: 690 .

10. No Authors Listed (2017) Cannabinoid hyperemesis syndrome.

11. Chang YH, Windish DM (2009) Cannabinoid hyperemesis relieved by compulsive bathing. Mayo Clin Proc 84: 76-78.

12. HowlettAC, Johnson MR, Melvin LS, Milne GM (1988) Nonclassical Cannabinoid analgetics inhibit adenylate cyclase: development of a cannabinoid receptor model. Mol Pharmacol 33: 297-302.

13. Galli JA, Sawaya RA, Friedenberg FK (2011) Cannabinoid hyperemesis syndrome. Curr Drug Abuse Rev 4: 241-249.

14. No Authors Listed (2017) Management of substance abuse: Cannabis.

15. Sun S, Zimmermann AE (2013) Cannabinoid hyperemesis syndrome. Hospit Pharm 48: 650-655.

16. Chen J, McCarron RM (2013) Cannabinoid hyperemesis syndrome: A result of chronic, heavy cannabis use. Curr Psych 10: 48-54. 